Proceedings of the 2nd international conference Economic and Business Trends Shaping the Future | 2021

\title{
FISCAL POLICIES IN PANDEMIC TIMES: EUROPEAN EXPERIENCES
}

\author{
Gligor Bishev \\ Faculty of Economics in Prilep, St. Kliment Ohridski in Bitola) and Sparkasse Bank Skopje \\ bishevgligor@gmail.com
}

\begin{abstract}
Aleksandar Stojkov
Iustinianus Primus Faculty, Ss. Cyril and Methodius University in Skopje

a.stojkov@.pf.ukim.edu.mk
\end{abstract}

Fatmir Besimi

Faculty of Business and Economics, South East European University and Ministry of Finance fatmir.besimi@finance.gov.mk

\begin{abstract}
The pandemic recession was fundamentally different from ordinary recessions, and thus required a different policy response. We review the empirical literature on fiscal consolidation and fiscal multipliers. Then, we assess the impact of fiscal policies on the pace of recovery and public debt sustainability. A premature or a strong fiscal consolidation might result in lower rates of economic growth and elevated public debt as a share of GDP. We critically analyze different adjustment paths across Europe and offer policy-relevant recommendations. The issue is particularly relevant for countries with a strong fiscal stimulus and moderate to high levels of public debt.
\end{abstract}

Key words: economic recovery; fiscal stimulus; public debt; sustainability.

JEL classification: H30; H62; F34.

\section{INTRODUCTION}

The pandemic recession in 2020 caused a sharp and sudden economic contraction across the globe. The economic calamity was a result of disrupted global supply chains, eroded consumer and investor confidence, strict health prevention measures (incl. international travel bans), limited fiscal space for intervention, etc. Nevertheless, the immediate government responses limited a more severe socio-economic impact and protected a large share of vulnerable households and firms. Many European governments vigorously responded to the medical and socio-economic emergencies by designing and implementing flexible fiscal policies and large fiscal stimulus packages.

Another indication of the magnitude of the crisis was the activation of the general escape clause at the EU level, effectively leading to a temporary suspension of European fiscal rules since March 2020. The goal of this policy change was to enable member states to take emergency measures against the pandemic crisis. The reactivation of the fiscal rules is now foreseen not before the end of 2022, contingent on a new political agreement on reforming the fiscal framework (e.g., Martin, Pisani-Ferry and Ragot, 2021).

In light of the high level of uncertainty, there is a difference in fiscal projections by international financial institutions regarding the European economies in 2021. Fiscal deficits in EU and euro area in 2021 are projected to either slightly decline as pandemic-related support expires (IMF, 2021) or slightly increase by $1 / 2$ and $3 / 4$ a percentage point of GDP (European Commission, 2021a).

http://hdl.handle.net/20.500.12188/15919

http://doi.org/10.47063/EBTSF.2021.0007 
One thing is for certain, the governments of European countries will continue to provide sizeable fiscal stimulus packages. According to the European Commission (2020), the EU member States have taken sizeable fiscal measures in response to the pandemic (4.2\% of GDP in 2020 and 2.4\% of GDP in 2021). On average, the advanced European economies allocated greater stimulus packages to support the fragile economic recovery. The fiscal support by the European peripheral economies and EU candidate countries is lower, given their limited fiscal space and overstretched public finances. As of October 2021, the direct health toll of the crisis is still unclear, as COVID19 infections started to surge again because of the rapidly spreading delta variant.

The central goal of this paper is to evaluate fiscal experiences in Europe and outline the main challenges for fiscal policy in the post-pandemic context. This is particularly relevant, given that the Global Financial Crisis 2008-09 provides limited experience and guidance in combatting the pandemic-induced recession. Since Europe itself is a rather homogenous group, we focus on several country groups based on their political and institutional proximity: (i) EU member states (EU27); (ii) 15 “old” EU member states (EU15); (iii) eight new EU member states from Central and Eastern Europe (CEE8); and (iv) EU candidate countries from Western Balkans (WB6). ${ }^{1}$ The more specific research questions are: (i) to assess the recent fiscal and related institutional developments in Europe; (ii) to explore whether the discretionary fiscal policy responses to COVID-19 were effective so far; and (iii) to outline the priorities for the fiscal policies in the postpandemic period.

The structure of the paper is as follows. The next section provides a critical review of the most recent academic studies of fiscal and related institutional policies in Europe. The most recent fiscal developments across Europe are presented in the third section. The empirical investigation of the nexus between fiscal balances and (contemporaneous and past) economic growth is provided in the next section. The fifth section elaborates the concluding remarks along with policy recommendations.

\section{LITERATURE REVIEW}

We confine our literature review only on the most recent academic studies of fiscal and institutional developments in Europe. Given the brief time span since the pandemic outbreak, most publications exist either as working papers or academic columns. This crisis is indeed different, as the shocks affect both aggregate demand and the aggregate supply. In many ways it is different from prior pandemics in terms of the economy, the policy response, and the shutdowns (Kennedy, 2020).

\subsection{Time for reflection on the European fiscal rules}

As already outlined in the introduction, in response to the pandemic crisis, the EU resorted to activation of the general escape clause of the Stability and Growth Pact on March 20th, 2020

\footnotetext{
${ }^{1}$ Since Europe is a heterogenous group, we differentiate several country groups based on the political and institutional arrangements:

- $\quad$ EU27: 27 European Union (EU) member states

- EU15: 15 EU member states prior to the accession of ten candidate countries on 1 May 2004 (Austria, Belgium, Denmark, Finland, France, Germany, Greece, Ireland, Italy, Luxembourg, Netherlands, Portugal, Spain, Sweden, United Kingdom)

- $\quad$ CEE8: Eight new EU member states from Central and Eastern Europe (Czech Republic, Estonia, Hungary, Latvia, Lithuania, Poland, Slovak Republic, and Slovenia) and

- WB6: Six countries from the Western Balkans (Albania, Bosnia and Herzegovina, Kosovo, Montenegro, North Macedonia, and Serbia).
} 
(European Commission, 2020). ${ }^{2}$ This is an effective temporary suspension of the fiscal rules until the end of 2022. As underscored by the EU Commissioner for Economy, Paolo Gentiloni in March 2021, "For 2022, it is clear that fiscal support will still be necessary: better to err towards doing too much rather than too little" (Valero, 2021).

Even well before the pandemic, there was a discontent with the rules-based approaches to govern national debt and budget deficits. For instance, Bilbiiie, Monacelli and Perotti (2021) openly criticize the European debt rules as "largely ineffective". This is especially relevant for the EU and euro area member states with highly persistent differences in their economies, which cannot be mitigated even with large, persistent, and unidirectional transfers to the distressed countries from Southern Europe.

In the past decade, many economists and public officials were calling for a major reform of the European fiscal rules (e.g., Bénassy-Quéré et al. 2018; Darvas et al. 2018a, 2018b; Feld et al. 2018, Thygesen et al. 2018). For instance, Beetsma et al. (2018) argue that the network of European fiscal rules and exceptions, resulting from the political compromises of the past two decades, have made the fiscal framework confusing, subjective, and arbitrary in its enforcement.

Blanchard, Leandro and Zettelmeyer (2021) argue for replacing budgetary rules by qualitative standards. They propose elimination of all numerical fiscal rules in favor of fiscal standards, i.e., qualitative prescriptions that leave room for judgment. Central to this judgment would be countryspecific assessments using stochastic debt sustainability analysis, led by national independent fiscal councils and/or the European Commission. Martin, Pisany-Ferry and Ragot (2021) move a step forward and propose country-specific debt targets. More precisely, they underscore that "uniform numerical criteria are misplaced because debt sustainability depends fundamentally on the differential between the interest rate and the growth rate and on a state's capacity to maintain a sufficient primary surplus." How feasible would this be - in political terms - is another challenge. Thygesen et al. (2020) also call for a reform of the European fiscal rules without a delay. They underscore the low compliance to the Stability and Growth Pact (SGP). For example, the European Commission (2021a) found that ten countries fell short of the SGP's required fiscal adjustments by a large margin (Belgium, Estonia, Spain, France, Hungary, Poland, Portugal, Slovenia, Slovakia, and the UK) while three were unsuccessful in reducing their high debt levels at the required pace (Belgium, France, and Spain). Some of their main conclusions are that the EU fiscal framework needs to be simplified and more effective, and growth-enhancing budget needs must be protected.

Even in times of crisis, there have been improvements of the fiscal rules' framework in the Western Balkans. For instance, the enactment of the new organic Budget Law (OBL) and the ensuing introduction of fiscal council and fiscal rules in North Macedonia are expected to further strengthen the fiscal discipline and transparency.

\subsection{Fiscal policies in the pandemic period}

\footnotetext{
2 The general escape clause allows Member States to undertake budgetary measures to deal adequately with such situation, within the preventive and corrective procedures of the Stability and Growth Pact. Specifically, for the preventive arm, Articles 5(1) and 9(1) of Regulation (EC) 1466/97 state that "in periods of severe economic downturn for the euro area or the Union as a whole, Member States may be allowed temporarily to depart from the adjustment path towards the medium-term budgetary objective, provided that this does not endanger fiscal sustainability in the medium term". For the corrective arm, Articles 3(5) and 5(2) stipulate that in the case of a severe economic downturn in the euro area or in the Union as a whole, the Council may also decide, on a recommendation from the Commission, to adopt a revised fiscal trajectory.
} 
Budget deficits and debt-to-GDP ratios recorded the largest ever increase in a single year in the post-WWII history of Europe. Much of the academic and policy focus during the ongoing health crisis has been on designing a centralized European fiscal response and to a lesser extent on national fiscal policies.

Devereux et al. (2020) highlight that early monetary policy responses to the crisis have shown that monetary policy alone cannot counter the detrimental effects of Covid-19 on the real economy. Within the discretionary fiscal measures, they make a distinction between direct liquidity support and measures aiming to change behaviour. In the same spirit, Bilbiie, Monacelli and Perotti (2021, p. 78) underscore that budget deficits and government debt have become "even more central to the debate on the reform of the eurozone, at least until the pandemic recession".

Faria-e-Castro (2021) focuses on the magnitude of fiscal multipliers during pandemic. He finds that a pandemic shock changes the ranking of policy multipliers. Unemployment benefits are the most effective tool to stabilize income for borrowers, who are the hardest hit during a pandemic. Cuesta Aguirre and Hannan (2021) study recoveries after pandemics and discover that countries that had provided higher fiscal support had comparatively better output outcomes, with an output decline of $1.5 \%$ after three years, compared to $3.4 \%$ for those with relatively low support. Ma, Rogers, and Zhou (2020) take a much longer historical perspective and conclude that, when fiscal support encompasses higher budget expenditure (especially in the health system), economies enjoy more bounce-back in output growth compared to countries with less of a fiscal expenditures' response.

Regarding the post-pandemic context, the scarce academic literature focuses on the growthconducive impact of the Next Generation EU, an unparalleled tool that provides significant financial support for reforms and investment, resulting in a coordinated fiscal expansion across the EU (e.g., Verwey, Langedijk and Kuenzel (2020); Bankowski et al. (2021); Mahieu et al. (2021); Pfeiffer, Varga and Veld (2021).

\section{RECENT FISCAL DEVELOPMENTS IN EUROPE}

Multiple strikes in the circular flow of income. From a macroeconomic perspective, the COVID19 pandemic produced (and still produces) multiple strikes on the circular flow of the national economy, which are illustrated in Figure 1. The disruptions caused by these strikes put a strong upward pressure on the unemployment and poverty rates and threaten to wipe out some of the precrisis development achievements. 
Figure 1. COVID-19's multiple strikes in the circular flow of income diagram

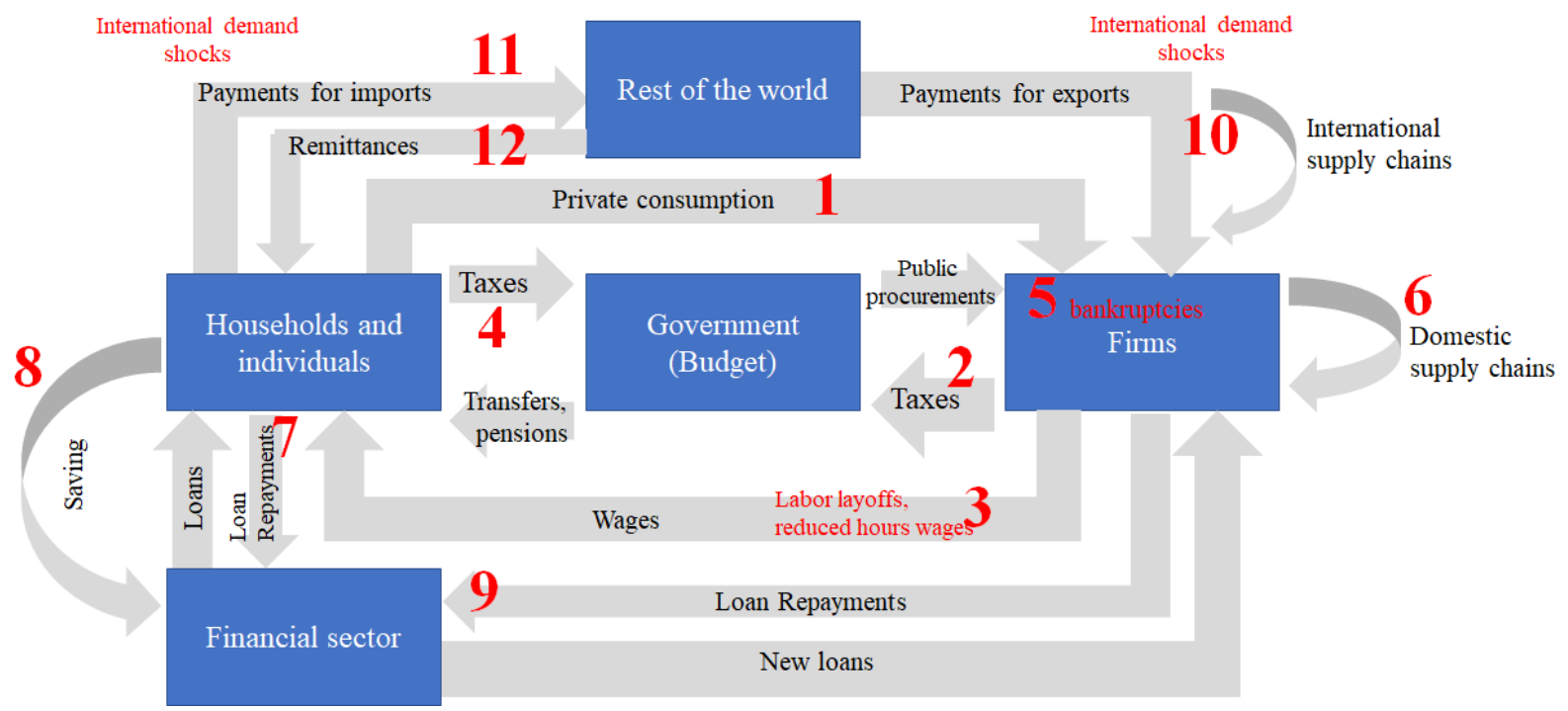

Source: Adaptation of a simpler diagram from Baldwin, Richard (2020), "Keeping the lights on: Economic medicine for a medical shock", VoxEU.org, March 13 ${ }^{\text {th }}, 2020$.

Unfavorable initial conditions. As opposed to the Global Financial Crisis (2008-09), the European countries had higher public debt levels and much lower fiscal space to tackle the pandemic recession (Figure 2). The gross general government levels in percent of GDP at end-2019 were much higher than those observed in pre-crisis 2007 across all groups of European economies: EU27, EU15, the eight EU member states from Central and Eastern Europe, and Western Balkans (WB6).

Figure 2. Gross general government debt (in percent of GDP), 2019 vs. 2007

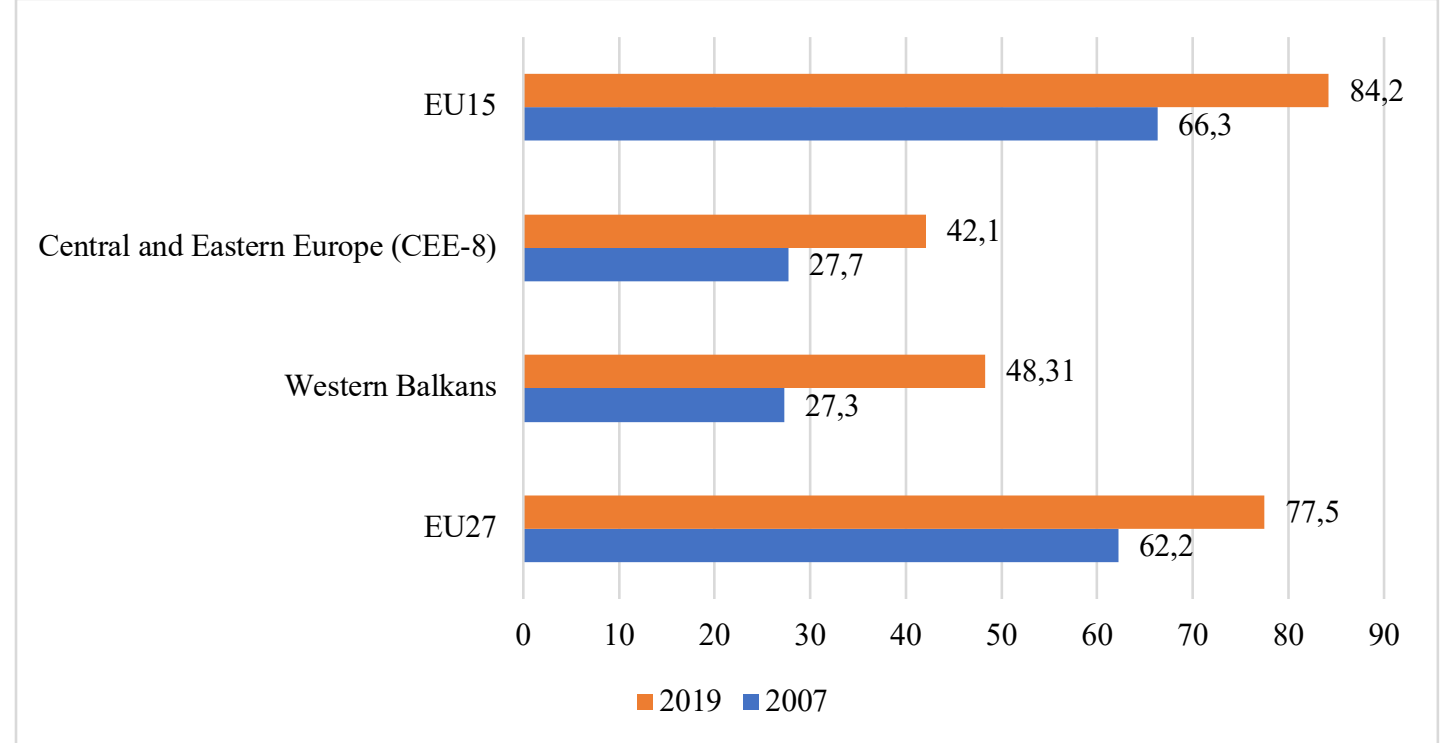

Source: Authors' calculations based on data from IMF World Economic Outlook Database (October 2021). 
Unprecedented fiscal challenges. Fiscal challenges associated with the pandemic recession in 2020 were unparalleled in the past two decades. It is not surprising therefore that the amount of fiscal support in 2020 was much larger than the historical norm for business cycle fluctuations (IMF, 2021). General government budget deficits as a share of GDP - or simply, fiscal deficits - were significantly higher than those observed during the Global Financial Crisis and the European sovereign debt crisis $(2008 / 10)$. It is estimated that nearly half of the increase in public deficits is due to the discretionary fiscal measures and the other half due to the workings of automatic stabilizers (European Commission, 2021a).

As presented in Figure 3, the average general government deficit (in percent of GDP) in EU27 in 2020/21 is projected to be $37 \%$ higher than the average budget deficit recorded during the Global Financial Crisis (2008-10). Public finances in the six countries of Western Balkans (WB6), on average, deteriorated even more significantly. The average fiscal deficit of $6.7 \%$ of GDP forecasted for the 2020/21 period is more than twice higher than the average fiscal deficit during the $2008 / 10$ period (3.1\% of GDP). Put differently, the crisis impact and the response of fiscal policy to the Covid-19 emergencies have been unprecedented in speed and size.

Figure 3. Global Financial Crisis vs. Pandemic recession: Average fiscal balances in percent of $G D P$

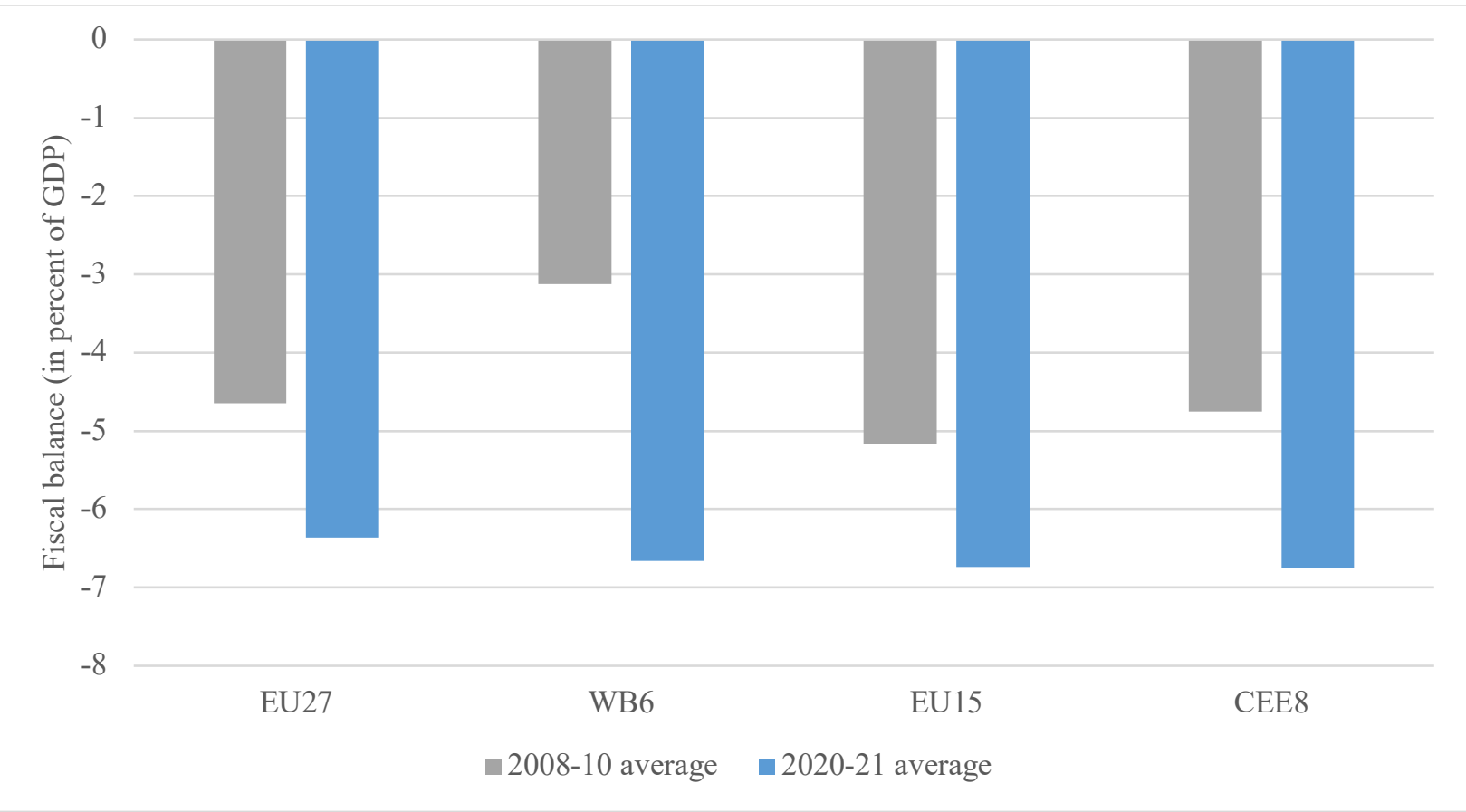

Source: Authors' calculations based on data from IMF World Economic Outlook Database (October 2021).

Proportional fall in budget revenue. The rise in deficits in advanced European economies resulted from roughly equal increases in spending and declines in revenues, whereas in CEE8 and WB6 countries, it stemmed primarily from the drop in revenues caused by the economic downturn. Figure 4 illustrates that the fall of general government budget revenue in 2020 (compared to 2019) was in the range between $-13.9 \%$ (Montenegro) and $-0.33 \%$ (Romania). However, since the revenue reduction was proportional to the economic contraction, the share of general government budget revenue in GDP was only slightly lower than the pre-crisis period across all groups of 
European economies (Figure 5). A mild decline in government revenue as a share of GDP is only observed in the WB6 region.

Figure 4. Drop in general government budget revenue (annual percent change, 2020/2019)

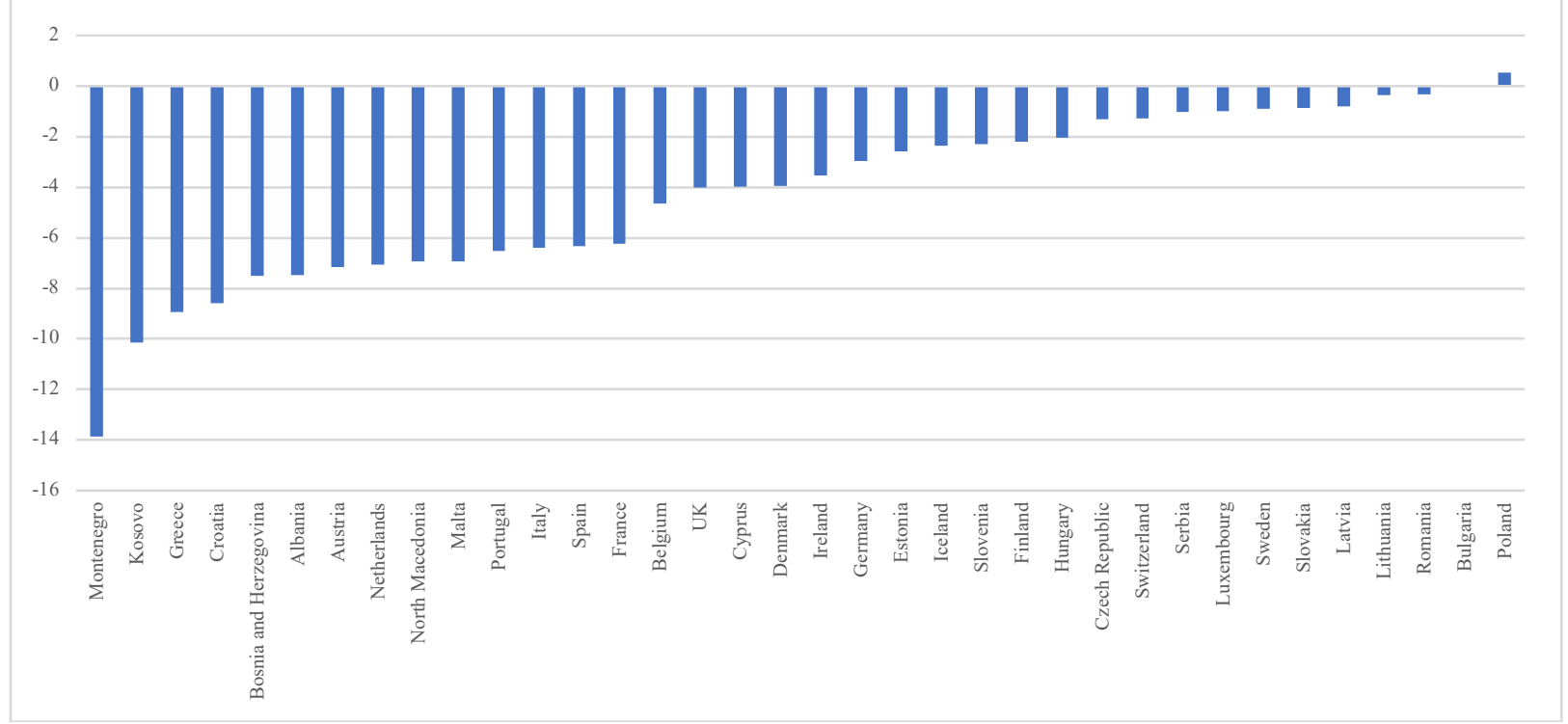

Source: IMF World Economic Outlook Database (October 2021).

Figure 5. General government budget revenue (in percent of GDP, 2000-2026)

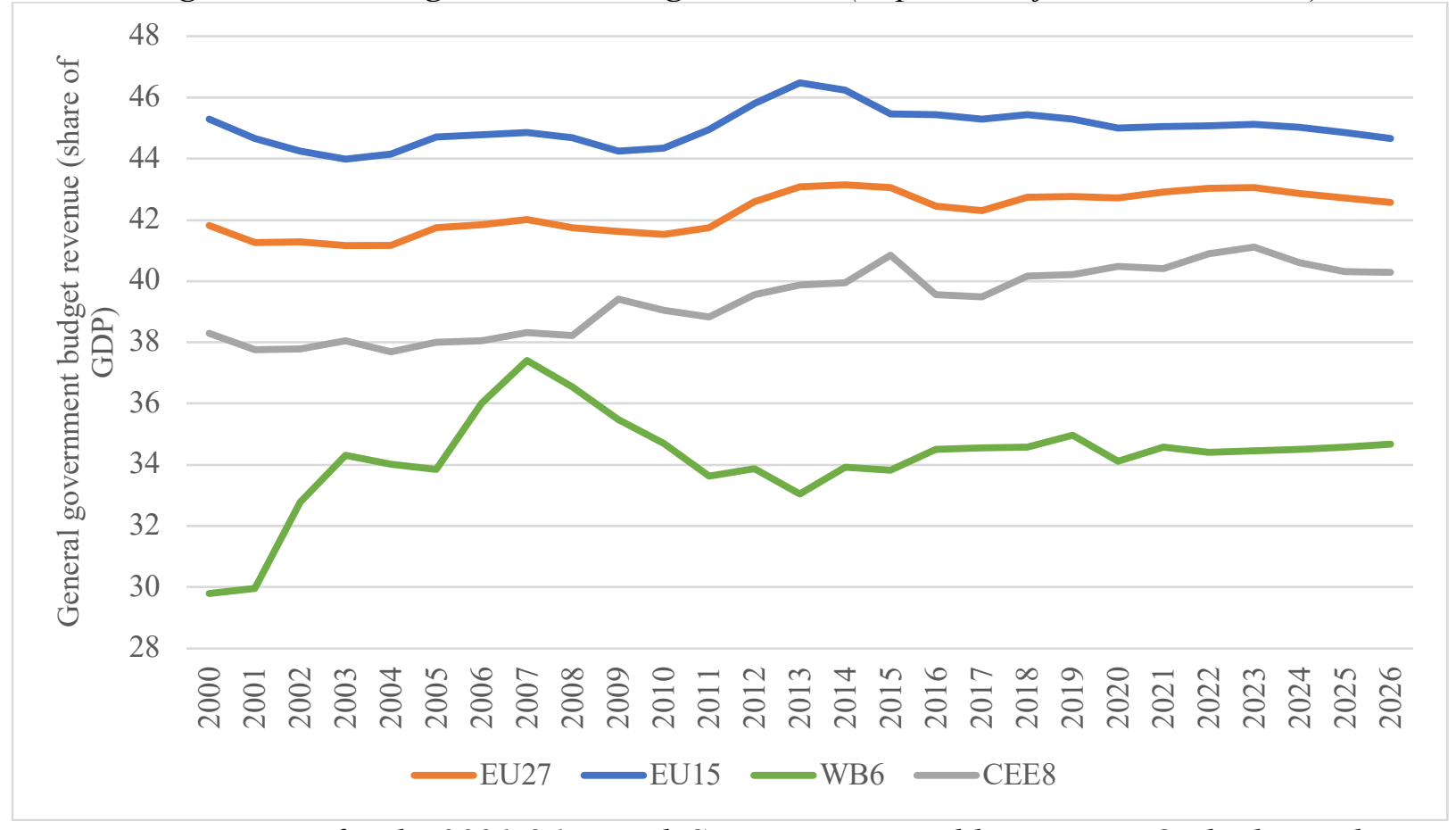

Note: Projections for the 2021-26 period. Source: IMF World Economic Outlook Database (October 2021).

Safeguarding capital expenditure. In the EU member states, the implementation of the national Recovery and Resilience Plans under the Next Generation EU programme is likely to strengthen 
the pace of recovery (European Commission, 2021a). Most European governments understand the need to preserve capital and other growth-enhancing expenditure to improve the medium-term prospects of recovery and growth.

Public debt accumulation. Since the sizeable fiscal stimulus packages were accompanied by a drop in budget revenues, the increase of public debt levels was a norm, rather than an exception (Figure $6)$.

Figure 6. Debt accumulation during the global financial crisis and the pandemic recession

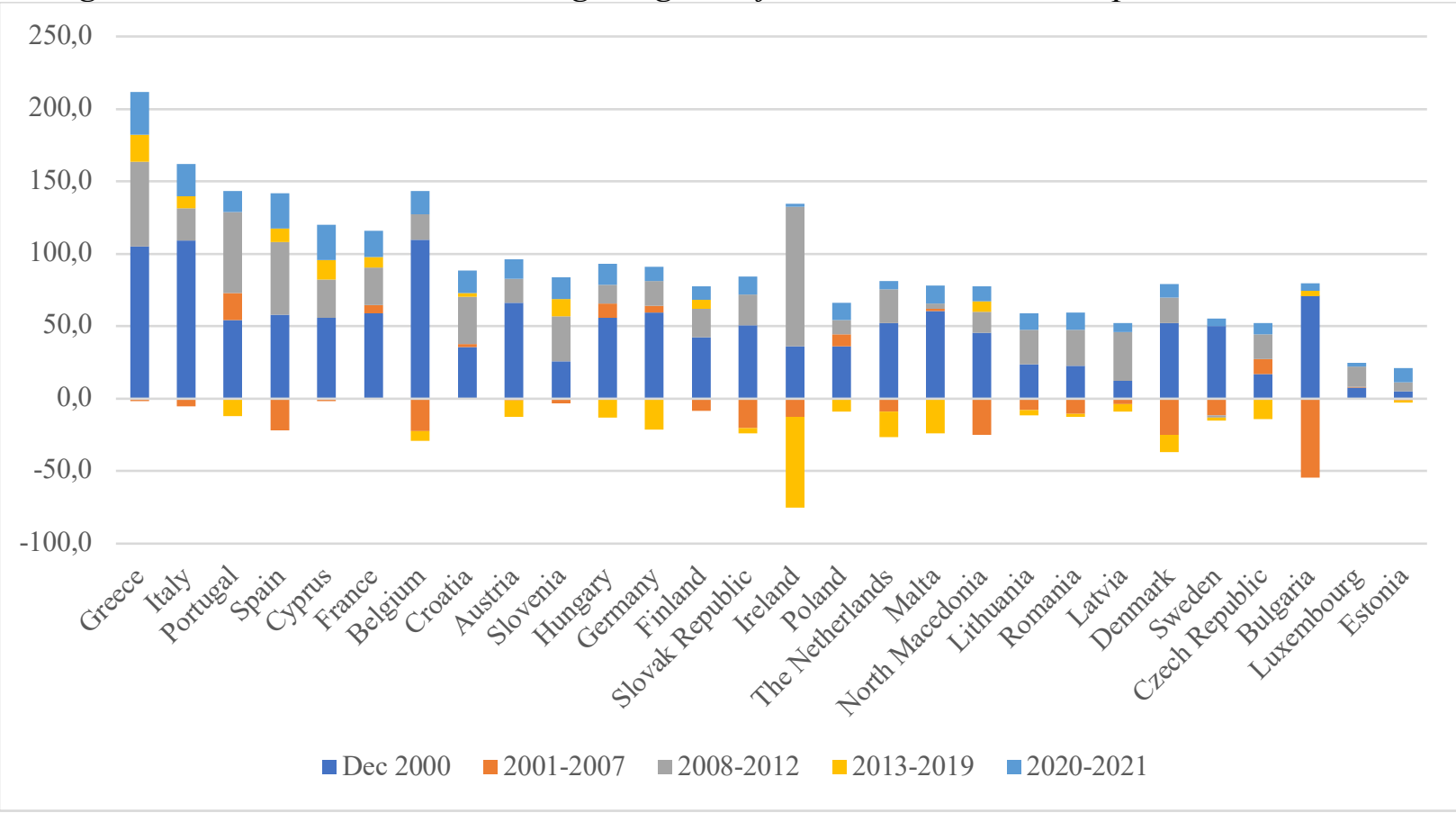

Source: Authors' calculations based on data from Eurostat (2021).

In the EU27, the government debt-to-GDP ratio increased from $77.5 \%$ at the end of 2019 to $90.7 \%$ at the end of 2020 , while in the euro area it increased from $83.9 \%$ to $98.0 \%$. For comparison only, average public debt across the globe reached an unprecedented 97 percent of GDP in 2020 and is projected to stabilize at around 99 percent of GDP in 2021.

Fiscal impulse. The research by the European Commission (2021) for the euro area reveal a mildly procyclical expansionary fiscal impulse in the 2016-19 period, followed by strong and abrupt shift to countercyclical expansionary fiscal impulse in 2020 (Figure 7). If the pace of recovery is satisfactory, the procyclical expansionary fiscal impulse will resume in 2021. A countercyclical restrictive fiscal impulse is estimated for 2022, when most euro area countries would return to the pre-crisis growth trajectory. 
Figure 7. Euro area fiscal impulse and degree of economic slack

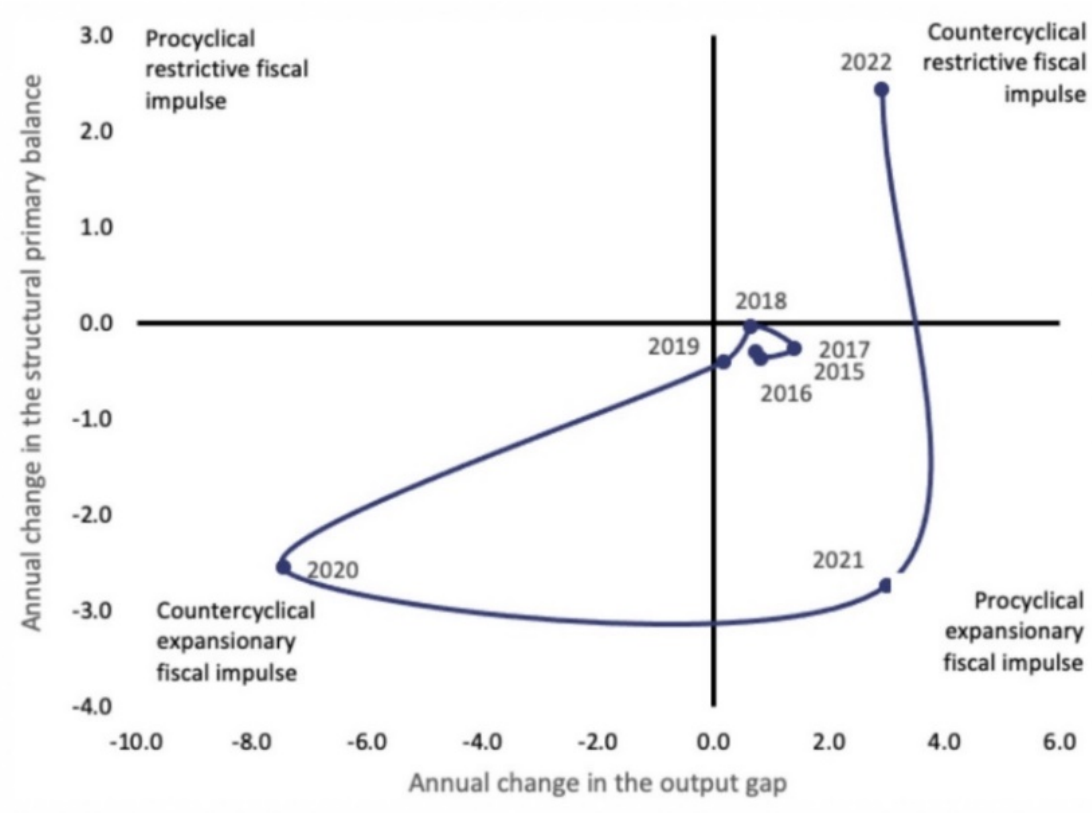

Source: European Commission (2021a).

Having outlined the main stylized facts on the fiscal arena in Europe, we now elaborate our empirical strategy, selected econometric methods, and the results.

\section{EMPIRICAL APPROACH}

It is a well-established fact in macroeconomics that fiscal balances and economic growth are endogenously determined variables due to their simultaneity. Higher rates of economic growth often generate higher budget revenue, which depending on the magnitude of the budget expenditure response, usually translates into an improved fiscal position. On the other hand, higher fiscal deficits are often justified on presumably strong fiscal multipliers that would foster economic recovery and growth acceleration.

The academic literature on fiscal multipliers is vast and beyond the scope of this paper. Many empirical studies have used quarterly data, introduced a distinction between government revenue and expenditure, and examined their relationship with country's Gross Domestic Product (GDP). The most commonly used empirical techniques for assessing the variable of interest (fiscal multipliers) are the structural Vector Autoregression (SVAR) or panel Vector Autoregressions (panel VARs). In theory, the fiscal multiplier is defined as the ratio of a change in output to an exogenous change in government spending $(\Delta \mathrm{G})$ or tax revenue $(\Delta \mathrm{T})$ with regard to their respective baselines (Batini et al. 2014). The assessment of fiscal multipliers provides valuable information to fiscal policymakers in: (i) evaluating the effects of fiscal policy: (ii) estimating the growth impact of fiscal stimulus or contraction; (iii) predicting the necessary adjustment and achievement of fiscal targets, such as the budget deficit or the debt-to-GDP ratio, etc.

We examine the nexus between economic growth and fiscal balances in Europe by employing two different empirical specifications: (i) a parsimonious specification of the empirical determinants of fiscal balances (in percent of GDP) as a dependent variable; and (ii) a medium-term growth specification based on a Bayesian averaging of classical estimates. 


\subsection{The impact of economic growth on fiscal balances}

\subsubsection{Empirical strategy}

From an econometric standpoint, the difference generalized method of moments (GMM) based on Arellano and Bond (1991) regression and the system GMM based on Arellano and Bover (1995) and Blundell and Bond (1998) models enable appropriate treatment of the hypothesized current account dynamics. Both are discussed in turn. The first-differenced Arellano and Bond (1991) GMM specification is particularly suitable for empirical analysis of panels with many crosssectional units and relatively short time series. Their procedure uses the GMM estimation, which is a semi parametric estimation that relaxes some of the assumptions of the other methods (maximum likelihood and least squares estimation methods). An important advantage of the GMM estimation is that it may use more moments than there are parameters to be estimated. The instrumentation is necessary to overcome the problem of endogeneity, which is present in both fixed-effects and random-effects static panel data models with lagged dependent variables. The first-differenced Arellano and Bond (1991) GMM specification has the following form:

$$
y_{i t}=\sum_{j=1}^{p} \alpha_{j} y_{i, t-j}+x_{i t} \beta_{1}+w_{i t} \beta_{2}+v_{i}+\varepsilon_{i t}
$$

where the variable $y_{i t}$ is observed for the unit $i$ at period $t, x_{i t}$ is a vector of exogenous variables and $w_{i t}$ is a vector of endogenous variables, $v_{i}$ stands for the unobserved country-specific effects, $\left|\alpha_{j}\right|<1$, and $\varepsilon_{i t}$ are identically and independently distributed error terms over the whole sample. Both $x$ and $w$ may contain lagged independent variables and the empirical specification should also include time dummies (Roodman, 2006). Because the country-specific effects $v_{i}$ are correlated with the past value of the dependent variable, the equation [2] is differenced to give (assuming just one lag of the dependent variable):

$$
y_{i t}-y_{i, t-1}=\delta\left(y_{i, t-1}-y_{i, t-2}\right)+\left(\varepsilon_{i t}-\varepsilon_{i, t-1}\right)
$$

so that the regression equation in differences allows elimination of the country-specific factors. The use of instruments is required to deal with possible endogeneity of the explanatory variables, which is reflected in the correlation between them and the error term, as well as with the correlation between the newly constructed error term $\left(\varepsilon_{i, t}-\varepsilon_{i, t-1}\right)$ and the differenced lagged dependent variable. The system GMM creates a system of two equations for each time period: the first one is based on the Arellano and Bond (1991) model in differences, in which differences are instrumented by levels, and an additional one in which the original levels are instrumented with differences (Roodman, 2006). One of the important innovations brought by the system GMM is that it circumvents the main problem of difference GMM, which is associated with the weak assumption that past levels of the variable are good instruments for first differences. More precisely, for variables that may be close to a random walk, past changes may be more predictive of current levels than past levels are of current changes. The system GMM uses more moment conditions because the explanatory variables expressed in first differences are instrumented with lags of their own levels, and the explanatory variables in levels are instrumented with lags of their own first differences. In panel datasets with a short time dimension and persistent time series, the Blundell and Bond (1998) version of the system GMM is found to bring "dramatic efficiency gains in 
comparison with the basic first-difference GMM" (Baltagi, 2005, p. 148). Hence, when the number of time periods available is small, the first-differenced GMM estimator may be subject to a large downward finite-sample bias (Blundell and Bond, 1998). For these reasons, the system GMM is the preferred estimation technique.

The instrumentation can apply to both the lagged dependent variable and to any other potentially endogenous explanatory variable. This additional advantage of the dynamic panel data model is used to address the potential endogeneity of several regressors. Given the formulation of the empirical model, there is strong theoretical justification to treat the contemporaneous growth pf GDP per capita and current account balance as jointly determined variables with the fiscal balance (the twin-deficit hypothesis).

The diagnostic $m 2$ test for both the general and the parsimonious empirical specification does not reject the null hypothesis of no second order autocorrelation of the residuals, while the $m 1$ test provides sufficient evidence that there is significant negative first-order autocorrelation in the residuals, as should be the case if the error term (in levels) is white noise. An inquiry into the statistical significance of a richer lag structure has also been conducted, but without significance of the second or the third lag. To avoid instrument proliferation, the number of instruments is limited to the maximum extent possible. All empirical results have been calculated by using the econometric software Stata 16.

\subsubsection{Empirical results}

The empirical investigation in determinants of the changes in fiscal balances in Europe is based on the estimation of the following parsimonious dynamic panel data model:

$$
f b_{i, t}=\alpha_{1} f b_{i, t-1}+\beta_{1} g r_{i, t}+\beta_{2} c a b_{i, t}+\delta_{i}+\mu_{t}+u_{i, t}
$$

where $f b_{i, t}$ refers to fiscal balances (in percent of GDP) as a dependent variable; $f b_{i, t-1}$ to past values of the dependent variable, $g r_{i, t}$ refers to growth of real GDP per capita (in PPP terms, in 2017 U.S. dollars); $c a b_{i, t}$ denote the current account balances (in percent of GDP); $\delta_{i}$ are sets of country dummies; $\mu_{t}$ denote the time effects and $u_{i, t}$ is the stochastic term. Subscripts $i$ and $t$ denote the cross-sectional units and the time period, respectively, so that $i=1,2, \ldots, 36(N=36)$, and $t=2000,1995, \ldots 2020(T=21)$. Since there are serious limitations in estimating cyclically adjusted fiscal balances for all European economies, we consider the original or unadjusted data. The empirical results refer to the relationship with contemporaneous growth of GDP per capita, which is explicitly modelled as an endogenous variable (Table 1) and with past year's growth of GDP per capita (Table 2). In addition to the entire period under investigation (2000-20), three subperiods are also taken into consideration: (i) the pre-crisis 2000-07 period; (ii) the crisis period (2008-12); and (iii) the post crisis 2013-20 period.

Both contemporaneous and past rates of growth of GDP per capita are important explanatory variables of fiscal balances. An acceleration of the real growth of GDP per capita by 1 percentage point is, on average, associated with an improvement of fiscal balances in the range between 0.284 and 0.605 percentage points of GDP, depending on the period under investigation (Table 1). To check whether the specification still suffers from a potential endogeneity problem, we replace contemporaneous growth of rates of real GDP per capita with their past values $\left(g r_{i, t-1}\right)$.

As presented in Table 2, lagged GDP growth (in PPP and per capita terms) is also a statistically and economically significant driving forces of fiscal balances in Europe. However, the coefficient 
is of a smaller magnitude and in the range between 0.138 and 0.294 (Table 2). A similar study by Tujula and Wolswijk (2004) finds that income elasticity of the budget was 0.15 during the 19702002 period.

Table 1. European sample: System GMM results with contemporaneous growth of GDP per capita

Dependent variable: Fiscal balance (in percent of GDP), Annual data (2000-20)

\begin{tabular}{|c|c|c|c|c|}
\hline \multirow{3}{*}{ Explanatory variables } & \multicolumn{4}{|c|}{ European sample } \\
\hline & \multirow{2}{*}{$\begin{array}{l}\text { Entire period } \\
2000-20\end{array}$} & \multicolumn{3}{|c|}{ Sub-periods } \\
\hline & & $2000-07$ & $2008-12$ & $2013-2020$ \\
\hline \multirow{2}{*}{$\begin{array}{l}\text { Lagged fiscal balance } \\
\text { (In percent of GDP) }\end{array}$} & $0.675^{* * *}$ & $0.891 * * *$ & $0.602 * * *$ & $0.438 * * *$ \\
\hline & {$[0.047]$} & {$[0.066]$} & {$[0.064]$} & {$[0.109]$} \\
\hline \multirow{2}{*}{$\begin{array}{l}\text { Growth of GDP per } \\
\text { capita }\end{array}$} & $0.284 * * *$ & $0.303 * * *$ & $0.399 * * *$ & $0.605 * * *$ \\
\hline & {$[0.030]$} & {$[0.103]$} & {$[0.041]$} & {$[0.078]$} \\
\hline \multirow{2}{*}{$\begin{array}{l}\text { Current account balance } \\
\text { (In percent of GDP) }\end{array}$} & $0.096^{* * *}$ & 0.005 & $0.140 * * *$ & $0.082 * *$ \\
\hline & {$[0.028]$} & {$[0.026]$} & {$[0.048]$} & {$[0.037]$} \\
\hline \multirow[t]{2}{*}{ Dummy 2008} & -0.777 & & & \\
\hline & {$[0.585]$} & & & \\
\hline \multirow[t]{2}{*}{ Dummy 2020} & $-4.428 * * *$ & & & \\
\hline & {$[0.466]$} & & & \\
\hline \multirow[t]{2}{*}{ Constant } & $-1.093 * * *$ & $-1.061 * *$ & $-1.600 * * *$ & $-2.356 * * *$ \\
\hline & [0.199] & {$[0.419]$} & {$[0.308]$} & {$[0.307]$} \\
\hline Number of observations & 738 & 257 & 185 & 296 \\
\hline Number of countries & 37 & 37 & 37 & 37 \\
\hline
\end{tabular}

Notes: Contemporaneous growth of GDP per capita treated as an endogenous variable. Asterisks ***, **, and * indicate 1\%, 5\% and $10 \%$ level of significance. 
Table 2. European sample: System GMM results with past year's growth of GDP per capita Dependent variable: Fiscal balance (in percent of GDP), Annual data (2000-20)

\begin{tabular}{|c|c|c|c|c|}
\hline \multirow{3}{*}{ Explanatory variables } & \multicolumn{4}{|c|}{ European sample } \\
\hline & \multirow{2}{*}{$\begin{array}{c}\text { Entire } \\
\text { period } \\
\text { 2000-20 }\end{array}$} & \multicolumn{3}{|c|}{ Sub-periods } \\
\hline & & 2000-07 & 2008-12 & $\begin{array}{r}2013- \\
2020\end{array}$ \\
\hline \multirow{2}{*}{$\begin{array}{l}\text { Lagged fiscal balance } \\
\text { (In percent of GDP) }\end{array}$} & $0.631 * * *$ & $0.908 * * *$ & $0.449 * * *$ & $0.279 * *$ \\
\hline & {$[0.053]$} & {$[0.070]$} & {$[0.083]$} & {$[0.173]$} \\
\hline \multirow{2}{*}{$\begin{array}{l}\text { Lagged Growth of GDP per } \\
\text { capita }\end{array}$} & $0.196 * * *$ & 0.138* & $0.233 * * *$ & $0.294 * *$ \\
\hline & {$[0.047]$} & {$[0.122]$} & {$[0.080]$} & [0.128] \\
\hline \multirow{2}{*}{$\begin{array}{l}\text { Current account balance } \\
\text { (In percent of GDP) }\end{array}$} & $0.093 * * *$ & -0.011 & $0.134 * *$ & $0.225 * * *$ \\
\hline & {$[0.030]$} & {$[0.037]$} & {$[0.060]$} & [0.059] \\
\hline \multirow[t]{2}{*}{ Dummy 2008} & -1.087 & & & \\
\hline & {$[0.735]$} & & & \\
\hline \multirow[t]{2}{*}{ Dummy 2020} & $-6.637 * * *$ & & & \\
\hline & {$[0.440]$} & & & \\
\hline \multirow[t]{3}{*}{ Constant } & $-0.975 * * *$ & -0.431 & - & - \\
\hline & & & $1.929 * * *$ & $2.536 * * *$ \\
\hline & [0.267] & [0.429] & {$[0.425]$} & {$[0.735]$} \\
\hline Number of observations & 736 & 255 & 185 & 296 \\
\hline Number of countries & 37 & 37 & 37 & 37 \\
\hline
\end{tabular}

In the next stage, a multiplicative term for the variable of interest (growth of GDP per capita, in PPP terms) and an intercept dummy is introduced only for the Western Balkan (WB6) countries. If the country belongs to the Western Balkans, then WB6 is equal to one and zero otherwise. The results are presented in Table 3 . The multiplicative term is not statistically significant, implying that Western Balkans is not different from the European sample. 
Table 3. System GMM results: Multiplicative term for Western Balkans (WB6)

\begin{tabular}{|c|c|}
\hline Explanatory variables & $\begin{array}{r}\text { System GMM } \\
\text { Estimation }\end{array}$ \\
\hline \multirow[t]{2}{*}{ Lagged fiscal balance (In percent of GDP) } & $0.705^{* * *}$ \\
\hline & [27.23] \\
\hline \multirow[t]{2}{*}{ Growth of GDP per capita } & $0.235 * * *$ \\
\hline & [5.64] \\
\hline \multirow[t]{2}{*}{ WB6 Dummy x Growth of GDP per capita } & 0.006 \\
\hline & {$[0.12]$} \\
\hline \multirow[t]{2}{*}{ Current account balance (In percent of GDP) } & $0.083 * * *$ \\
\hline & [2.99] \\
\hline \multirow[t]{2}{*}{ Dummy 2008} & -0.792 \\
\hline & {$[-1.57]$} \\
\hline \multirow[t]{2}{*}{ Dummy 2020} & $-4.986 * * *$ \\
\hline & {$[-8.89]$} \\
\hline \multirow[t]{2}{*}{ Constant } & $-1.040 * * *$ \\
\hline & {$[-7.15]$} \\
\hline \multirow[t]{2}{*}{ Western Balkans (WB6) Dummy } & 0.454 \\
\hline & [1.26] \\
\hline Number of observations & 736 \\
\hline Number of countries & 37 \\
\hline
\end{tabular}

\subsection{The impact of economic growth on fiscal balances}

The analytical framework of the growth model builds upon the investigation by Sala-i-Martin et al. (2004) of the statistical significance of growth determinants. Their methodology is based on a Bayesian averaging of classical estimates and aims at narrowing the gap between the growth theories and the empirical work. The noted study examines the relationship between economic growth and a list of 67 explanatory variables (identified in the cross-country growth regressions from articles in peer-reviewed or refereed journals) using data for 88 countries.

The selection of the variables is based on the criteria of: (i) sufficient time length of the published or computed variables (from 1960 onwards) and (ii) maximisation of the product of the number of countries with observations for all variables and the number of variables. The strength of the association between each variable and economic growth is ranked according to the (posterior) inclusion probability. The latter is a measure of the weighted average goodness-of-fit of models including a particular variable, relative to models not including the variable.

From the narrow list of variables that is found to be significantly and robustly partially correlated with economic growth (eighteen, in particular) in the study by Sala-i-Martin et al. (2004), five are selected as core explanatory variables in the empirical model adopted here. As examined below, the inclusion of these five determinants (initial GDP per capita, human capital, population growth, and relative price of investment goods) has been strongly advocated by growth theories. 
The inclusion of the initial level of GDP per capita tests the propositions of the beta-convergence hypothesis, implying that low-income countries tend to display higher rates of growth. Hence, the expected sign of the coefficient on this variable is negative. The human capital indicator captures the important role of education and skills of the labor force. Given the lack of alternative education indicators, this measure plays a satisfactory role in many growth regressions. The relative price of capital goods serves as a proxy for the costs of investment. This measure is constructed as a ratio between the price level of investment and the GDP deflator. The empirical studies seem to offer compelling evidence in favour of a strong negative relationship between the relative price of capital goods and investment. As the accumulation of physical capital is growth conducive, the expected sign on the relative price of investment goods is negative.

A standard approach in the academic literature to mitigate the persistence in the time series of macroeconomic variables is to rely on multi-year intervals or averages. Therefore, the dependent variable is average growth of GDP per capita (in Purchasing Power Parity terms), organized in three-year non-overlapping intervals (1981-1983, 1984-1986, ..., 2017-2019). The decision to use three-year intervals is due to data availability issues. Using a five- or four-year non-overlapping intervals would produce insufficient number of observations for the sample of European countries. The insufficient number of observations is particularly pronounced for the transition economies when data is organized at the five- and four-year frequencies. Additionally, the longer the time spans at which data are considered, the smaller the standard deviation is.

Our second-best empirical strategy is to employ a fixed-effects panel data model as the main estimation technique when data is organized at the three-year frequencies. There are several arguments that support this empirical strategy: firstly, the fixed-effects panel data model is considered as an appropriate specification when focusing on a specific set of countries and when the inference is restricted solely to their behaviour (Baltagi, 2005). Secondly, the Hausmann specification test provides formal support for this estimation technique.

\section{Table 4. Growth specification (Fixed effects)}

Dependent variable: Average growth of GDP per capita (PPP), 1981-2019, three-year nonoverlapping intervals

\begin{tabular}{|l|r|c|}
\hline Explanatory variables & Coefficient & t-stat \\
\hline Initial GDP per capita (natural logarithm) & $-0.374 * * *$ & {$[-4.93]$} \\
\hline Population growth & $1.303 * *$ & {$[2.28]$} \\
\hline Human capital & $4.796 * *$ & {$[2.36]$} \\
\hline Relative price of investment & -4.964 & {$[-1.53]$} \\
\hline $\begin{array}{l}\text { Average fiscal balance in the previous three-year } \\
\text { period }\end{array}$ & $-0.161 * * *$ & {$[-3.19]$} \\
\hline Constant & $43.075 * * *$ & {$[5.85]$} \\
\hline & & \\
\hline Number of observations & 322 & \\
\hline Number of countries & 36 & \\
\hline
\end{tabular}

Notes: $t$-statistics in brackets, based on robust standard errors. Asterisks ***, **, and * indicate

$1 \%, 5 \%$ and $10 \%$ level of significance. The averages refer to three-year non-overlapping intervals (1981-1983, 1984-1986, ..., 2014-2016, 2017-2019), using fixed effects with clustered standard errors. Unless otherwise indicated, the values for the right-hand side variables are for 
the year preceding the three-year interval (e.g., 2016 for the 2017-2019 period). Constants and time dummies are not reported.

To address the problem of potential endogeneity, observations of the core explanatory variables refer to the year preceding the three-year non-overlapping interval (e.g., 2016 for the 2017-2019 period). An important exception is the fiscal balance (in percent of GDP), which enters either for the year preceding the interval or as average fiscal balances in the previous three-year interval. To minimize the potential problem of cross-sectional interdependence, all empirical specifications include period (time-specific) dummies, which are not reported here.

In line with the beta-convergence hypothesis, initial per capita income is negatively correlated with economic growth, implying that an increase in the initial per capita income of 1 percent, on average, is associated with 0.37 percentage points lower rate of medium-term growth of GDP per capita of the analyzed economies (see Table 4). In line with our a priori expectations, human capital is positively related to the medium-term rates of economic growth, whereas relative price of investment displays a negative association. Population growth has also a positive impact on the average growth of GDP per capita (in PPP terms).

The coefficient of interest is statistically significant and reveals strong and consistent impact of fiscal balances on the economic growth. A deterioration of the fiscal-balance-to-GDP ratio by 1 percentage point in the previous period is likely to be associated with 0.16 percentage points higher rate of medium-term economic growth, ceteris paribus. The result is also conditional on country's initial GDP per capita as a proxy for the level of economic development.

\section{CONCLUDING REMARKS}

Fiscal policy will continue to play a key role in the post-pandemic period. As the recovery takes hold, the policies should switch from damage control to strengthening the economic recovery and resilience of the national economies.

Our empirical evidence suggests that, during the past two decades, higher-growth periods led to improvement of fiscal positions across Europe, even when past year's growth was considered. An acceleration of the real growth of GDP per capita by 1 percentage point is, on average, associated with an improvement of fiscal balances in the range between 0.284 and 0.605 percentage points of GDP, ceteris paribus, depending on the period under investigation. The results also hold for the sub-sample of Western Balkan countries.

In the growth specifications referring to the 1981-2019 period, budget deficits in the previous three-year interval were associated with higher economic growth in the subsequent three-year period. A deterioration of the fiscal-balance-to-GDP ratio by 1 percentage point in the previous period is likely to be associated with 0.16 percentage points higher rate of medium-term economic growth, ceteris paribus. The result is also conditional on country's initial GDP per capita as a proxy for the level of economic development

In the near future, fiscal responses across Europe will continue to depend on health factors (rates of vaccination, effectiveness of vaccines, stringency of new containment measures) and real factors (the pace of economic recovery). Despite the high public debt levels, there is a growing consensus that fiscal policies should remain supportive and flexible. Fiscal policy priorities should include continuing support for the vulnerable households and viable firms.

There appears to be a growing consensus that European countries should avoid withdrawing fiscal support abruptly. A premature fiscal consolidation (an early withdrawal of the liquidity and financial support for affected companies and socially vulnerable households) would delay the 
economic recovery. A sharp fiscal contraction could easily result in lower rates of economic growth and elevated public debt as a share of GDP. The fiscal policy should therefore continue to support the economic recovery, the restructuring and acceleration of economic growth.

Different recovery paths are to be expected across Europe. Fiscal sustainability must be ensured by a credible medium-term fiscal framework outlining the authorities' commitment to the adjustment process. More precisely, feasible medium-term fiscal frameworks are needed to encapsulate a vision of gradual fiscal consolidation and a return to fiscally sustainable positions. This would also contribute to lower costs of sovereign borrowing and higher confidence by the financial investors.

Our views are in line with Blanchard, Leandro and Zettelmeyer (2021), implying that if the European fiscal rules are reinstated, they will need to be modified to account for elevated public debt levels and country specificities. Furthermore, rebuilding fiscal buffers and dealing with longstanding structural problems would be crucial for resilience in the event of further shocks.

\section{REFERENCES}

Arellano, M., Bond, S. (1991) Some Tests of Specification for Panel Data: Monte Carlo Evidence and an Application to Employment Equations, Review of Economic Studies 58 (2): 277-297. Arellano, M., Bover, O. (1995) Another Look at the Instrumental Variables Estimation of ErrorComponent Models, Journal of Econometrics 68 (1): 29-51.

Baltagi, B. (2005) Econometric Analysis of Panel Data, Third Edition, John Wiley \& Sons, Ltd. Bańkowski, K., M. Ferdinandusse, S. Hauptmeier, P. Jacquinot, and V. Valenta (2021) "The macroeconomic impact of the Next Generation EU instrument on the euro area", ECB Occasional Paper No. 2021/255.

Batini, Nicoletta, Luc Eyraud, Lorenzo Forni, and Anke Weber (2014) Fiscal Multipliers: Size, Determinants, and Use in Macroeconomic Projections. Technical Notes and Manuals. The International Monetary Fund, Washington D.C.

Beetsma, O., N. Thygesen, A. Cugnasca, E. Orseau, P. Eliofotou, and S. Santacroce (2018) "Reforming the EU fiscal framework: A proposal by the European Fiscal Board", VoxEU.org, 26 October.

Bénassy-Quéré, A., M. Brunnermeier, H. Enderlein, E. Farhi, C. Fuest, P. O. Gourinchas, P. Martin, J. Pisani-Ferry, H. Rey, I. Schnabel, and N. Véron (2018) "Reconciling Risk Sharing with Market Discipline: A Constructive Approach to Euro Area Reform", CEPR Policy Insight No. 91. Bilbiie, F., T. Monacelli, and R. Perotti (2021) "Fiscal Policy in Europe: Controversies over Rules, Mutual Insurance, and Centralization", Journal of Economic Perspectives 35(2): 77-100. Blanchard, O., Á. Leandro, and J. Zettelmeyer (2021) "Redesigning EU Fiscal Rules: From Rules to Standards", Peterson Institute for International Economics Working Paper No. 21/1. Blundell, R., Bond, S. (1998) Initial Conditions and Moment Restrictions in Dynamic Panel Data Models, Journal of Econometrics 87 (1): 115-143.

Cuesta Aguirre, J. P., and S. A. Hannan (2021), "Recoveries After Pandemics: The Role of Policies and Structural Features", IMF Working Paper Series WP/21/181.

Darvas, Z., P. Martin, and X. Ragot (2018a) "Reforming European Budgetary Rules: Simplification, Stabilization and Sustainability", Notes du CAE, no. 47, September 2018.

Darvas, Z., P. Martin, and X. Ragot (2018b) European Fiscal Rules Require a Major Overhaul. French Council of Economic Analysis. 
Devereux, M. P., I. Güçeri, M. Simmler, and E. H.F. Tam (2020) "Discretionary Fiscal Responses to the Covid-19 Pandemic", Oxford Review of Economic Policy, 36 (I): S225-S241.

European Commission (2020) The 2021 Draft Budgetary Plans: Overall Assessment, November. European Commission (2021a) Spring 2021 Economic Forecast: Rolling up sleeves.

European Commission (2021b), Debt Sustainability Monitor 2020, February .

Faria-e-Castro, M. (2021) "Fiscal policy during a pandemic", Journal of Economic Dynamics and Control, 125 (C): 104088.

Feld, L., C. Schmidt, I. Schnabel, and V. Wieland (2018) "Refocusing the European Fiscal Framework", VoxEU.org, 12 September.

Huidroma, Raju, Ayhan Kose, Jamus J. Lim, and Franziska L. Ohnsorge (2020) Why do fiscal multipliers depend on fiscal positions?, Journal of Monetary Economics, 114 (2020): 109-125.

Kennedy, S. (2020) Harvard's Reinhart and Rogoff Say This Time Really Is Different Simon Kennedy. https:/www.bloombergquint.com/coronavirus-outbreak/harvard-s-financial-crisisexperts-this-time-really-is-different, Interview, BloombergQuint, May 192020.

Ma, C., J. Rogers, and S. Zhou (2020) "Modern Pandemics: Recession and Recovery", International Finance Discussion Papers no. 1295. Washington DC: Board of Governors of the Federal Reserve System.

Mahieu, G., P. Pfeiffer, J. Varga, and J. in 't Veld (2021) A stylised quantitative assessment of Next Generation EU investment

Martin, P., J. Pisani-Ferry, and X. Ragot (2021) "Reforming the European Fiscal

Framework", Les notes du conseil d'analyse économique, no 63.

Pfeiffer, P, J Varga and J in 't Veld (2021), "Quantifying Spillovers of NGEU investment", European Economy Discussion Papers No. 144.

Roodman, D. (2006) How to Do xtabond2: An Introduction to "Difference" and "System" GMM in Stata, Working Paper No. 103, Center for Global Development, http://www.cgdev.org/ content/publications/detail/11619.

Roodman, D. (2007). A Short Note on the Theme of Too Many Instruments, Working Paper No. 125, Center for Global Development, August, (www.cgdev.org/files/ 14256_file_Instruments.pdf).

Sala-i-Martin, X., Doppelhofer, G., Miller, R. (2004) "Determinants of Long-term Growth: A Bayesian Averaging of Classical Estimates (BACE) Approach", American Economic Review 94 (4): 813-835.

Thygesen, N., R. Beetsma, M. Bordignon, S. Duchêne, and M. Szczurek (2018) Second Annual Report of the European Fiscal Board, European Budget Committee.

Thygesen, N., R. Beetsma, M. Bordignon, X. Debrun, M. Szczurek, M. Larch, M. Busse, M. Gabrijelcic, E. Orseau, and S. Santacroce (2020), "Reforming the EU fiscal framework: Now is the time" , VoxEU.org, 26 October.

Valero, J. (2021) "Commission wants to keep fiscal rules suspended in 2022.", Euractiv.com, March 3 $3^{\text {rd }}, 2021$. https://www.euractiv.com/section/economic-governance/news/commissionwants-to-keep-fiscal-rules-suspended-in-2022/

Verwey, M., S. Langedijk and R. Kuenzel (2020) "Next Generation EU: A recovery plan for Europe", VoxEU.org, 09 June. 